\title{
Self-organizing "harmonic dominance stripes" in a spiking network model of the auditory system
}

Marcos A Cantu ${ }^{1,2}$

From Twenty Second Annual Computational Neuroscience Meeting: CNS*2013

Paris, France. 13-18 July 2013

A model of the auditory system was developed which implements spike timing dependent plasticity (STDP) [1] in a biologically realistic network of spiking excitatory Izhikevich neurons [2]. The model self-organizes in response to periodic sound and exhibits "harmonic dominance stripes" (Figure 1A) in the STDP connectivity matrix between the two layers of the network. These "harmonic dominance stripes" are akin to the activity
A

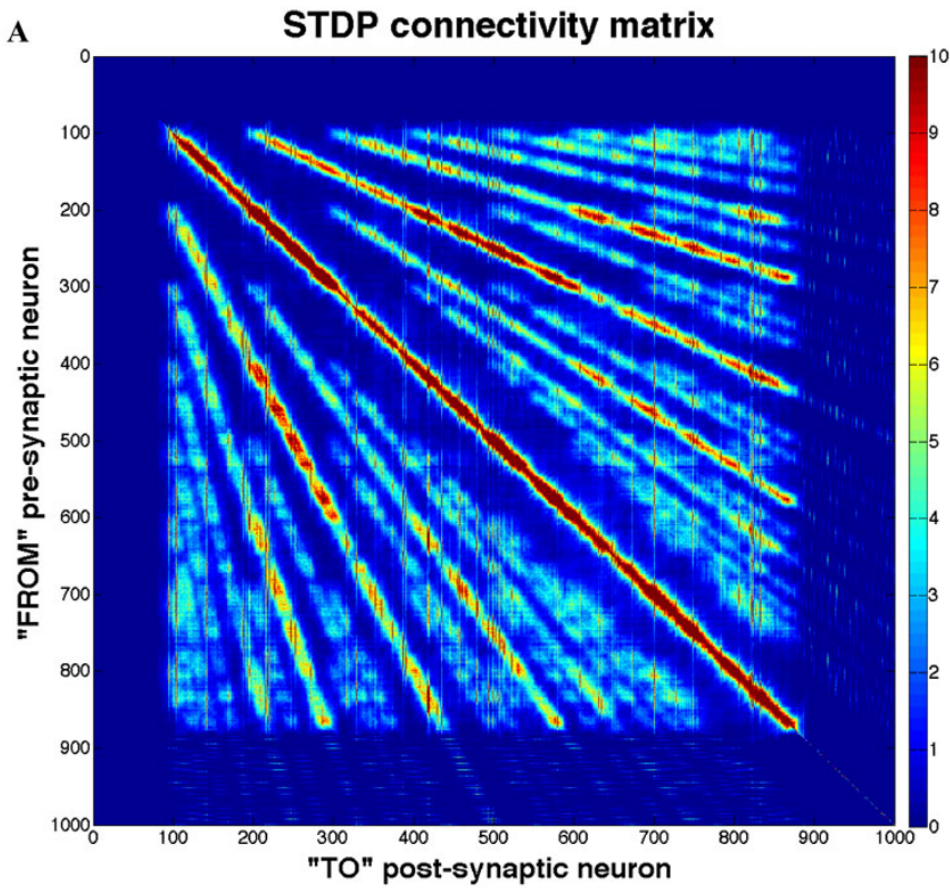

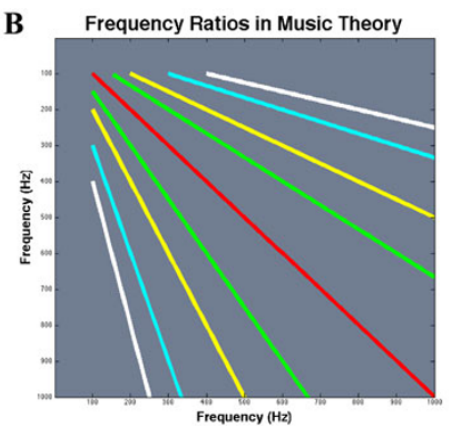

C

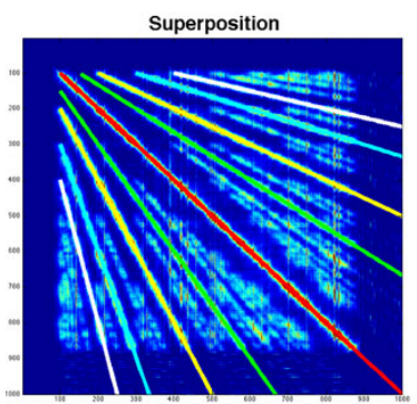

Figure 1 Self-Organizing "Harmonic Dominance Stripes" in a Spiking Network Model of the Auditory System A: Connectivity Matrix. After 500 trials, self-organizing "harmonic dominance stripes" had become clearly visible in the connectivity matrix between the two layers of neurons. Besides the "tonotopic" unison interval stripe along the diagonal, stripes corresponding to the octave and fifth intervals in Western music theory (see Figure $1 \mathrm{~B}$ and $1 \mathrm{C}$ ) were also clearly visible. The colorbar on the Right shows the strength of synaptic connections between neurons. B: Frequency ratios from 100 to $1000 \mathrm{~Hz}$ for Unison (red), Octave (yellow and white) and Perfect Fifth (green and cyan) intervals in Western music theory. C: Unison, Octave and Perfect Fifth Frequency ratios from Figure 1B superimposed over the STDP connectivity matrix from Figure 1A.

\footnotetext{
Correspondence: cantu@bu.edu
}

'Graduate Program for Neuroscience, Boston University, Boston, MA, 02215,

USA

Full list of author information is available at the end of the article 
dependent formation of "ocular dominance columns" in the visual system, as both are architectural features that emerge through a process of self-organization as a result of passive exposure to patterned sensory input during development. The self-organizing "harmonic dominance stripes" also happen to correspond to consonant intervals (Figure. 1B and $1 \mathrm{C}$ ) in music theory.

\section{Author details}

'Graduate Program for Neuroscience, Boston University, Boston, MA, 02215, USA. ${ }^{2}$ Center for Computational Neuroscience and Neural Technology

Boston University, Boston, MA, 02215, USA.

Published: 8 July 2013

\section{References}

1. Song $S$, Miller $K$, Abbott $L$ : Competitive Hebbian learning through spiketiming dependent synaptic plasticity. Nature Neuroscience 2000, 3(9):919-926.

2. Izhikevich EM: Simple model of spiking neurons. IEEE Transactions on Neural Networks 2003, 14(6):1569-1572, 2003.

doi:10.1186/1471-2202-14-S1-P52

Cite this article as: Cantu: Self-organizing "harmonic dominance stripes" in a spiking network model of the auditory system. BMC Neuroscience 2013 14(Suppl 1):P52.

\section{Submit your next manuscript to BioMed Central} and take full advantage of:

- Convenient online submission

- Thorough peer review

- No space constraints or color figure charges

- Immediate publication on acceptance

- Inclusion in PubMed, CAS, Scopus and Google Scholar

- Research which is freely available for redistribution

Submit your manuscript at www.biomedcentral.com/submit
C Biomed Central 